\title{
Upper gastrointestinal safety and tolerability of oral alendronate: A meta-analysis
}

\author{
MANRU ZHOU ${ }^{1 *}$, YAYUAN ZHENG ${ }^{2 *}$, JIN LI $^{1}$, JINGKAI WU $^{1}$, WEIMING XU ${ }^{1}$, \\ LIAO CUI $^{1}$, WEIMIN YAO ${ }^{3}$ and YUYU LIU ${ }^{1}$ \\ ${ }^{1}$ Department of Pharmacology, Guangdong Medical University; Departments of ${ }^{2}$ Pharmacy and ${ }^{3}$ Respiratory Medicine, \\ The Affiliated Hospital of Guangdong Medical University, Zhanjiang, Guangdong 524023, P.R. China
}

Received December 30, 2014; Accepted September 24, 2015

DOI: $10.3892 /$ etm.2015.2848

\begin{abstract}
Osteoporosis (OP), which is a common bone disease associated with reduced bone mineral density and disordered bone microstructure, may result in an increased risk of bone fracture. The present study aimed to investigate the frequency of alendronate (Aln)-associated upper gastrointestinal tract adverse events (GIAEs) in postmenopausal women with OP. The following databases were searched in order to identify relevant studies: Medline (using PubMed as the search engine), Embase, the Web of Science and the Cochrane Central Register of Controlled Trials (up to December 2014). Studies were selected for inclusion if they were randomized, double-blind, placebo-controlled trials, which had investigated the safety of Aln versus a placebo for the treatment of postmenopausal women with OP. The primary outcomes of the included studies were total adverse events (AEs) and upper GIAEs, whereas individual upper GIAEs were considered as secondary outcomes. The general characteristics and outcomes of each study were abstracted by two independent researchers, and Review Manager 5.3 software was used for data syntheses and the meta-analysis. A total of nine studies, including 15,192 randomized patients, met the inclusion criteria and contributed to some or all of the meta-analysis outcomes. The Mantel-Haenszel method was used to calculate risk ratios, and their 95\% confidence intervals (CI) were determined using either the fixed or random effects model, depending on the level of heterogeneity. The relative risk $(95 \% \mathrm{CI})$ of AEs associated with Aln treatment, as compared with the placebo group, was
\end{abstract}

Correspondence to: Professor Yuyu Liu, Department of Pharmacology, Guangdong Medical University, 2 Wenmingdong Road, Zhanjiang, Guangdong 524023, P.R. China

E-mail: liuyuyu77@163.com

Dr Weimin Yao, Department of Respiratory Medicine, The Affiliated Hospital of Guangdong Medical University, 57 Renmindadaonan Road, Zhanjiang, Guangdong 524023, P.R. China

E-mail: 490296443@qq.com

${ }^{*}$ Contributed equally

Key words: meta-analysis, alendronate, gastrointestinal, osteoporosis
1.01 (0.97-1.06), and the relative risk (95\% CI) of discontinued Aln treatment due to AEs was 1.04 (0.91-1.19). In addition, the relative risk (95\% CI) of upper GIAEs was 1.02 (0.99-1.06), and the relative risk $(95 \% \mathrm{CI})$ of discontinued Aln treatment due to upper GIAEs was $1.23(0.97-56)$. In addition, these results remained robust to sensitivity analyses. The results of the present study suggested that Aln has a good GI tract tolerability, and that daily treatment with $10 \mathrm{mg}$ Aln sodium does not increase the risk of GIAEs in postmenopausal women with OP.

\section{Introduction}

Osteoporosis presents a significant public health challenge, which contributes a substantial cost economically and in terms of morbidity and mortality. The disease is characterized by low bone mineral density and degeneration of the bone microarchitecture, which increases bone brittleness and fracture risk. Four key mechanisms appear to be crucially involved in the pathogenesis of this condition: i) Inhibition of osteoclast recruitment; ii) inhibition of osteoclastic adhesion; iii) shortening of the life span of osteoclasts due to earlier apoptosis; and iv) the inhibition of osteoclast activity. Bisphosphonates are the most widely available treatments for osteoporosis in postmenopausal women. Among these, alendronate (Aln), which has been used extensively and has the longest history in clinical practice, is recognized as a first-line drug for the treatment of OP (1-6). Previous studies have demonstrated that Aln is able to effectively reduce the risk of vertebral, non-vertebral, hip and wrist fractures (7-9). The safety and tolerability of Aln has previously been investigated in various randomized controlled trials (RCTs) and retrospective studies (10-18), and the majority of these have reported similar side effects, including gastrointestinal tract adverse events (GIAEs), for the Aln-treated and placebo-treated groups. It has been reported that oral administration of bisphosphonates, particularly those containing a nitrogen atom, may be accompanied by digestive tract disturbances (19). In addition, other bisphosphonates, as well as Aln, have been associated with GIAEs, which may be linked to reduced compliance (20-23). These findings suggest that Aln may cause GI tract disorders. Furthermore, oesophageal- and gastric-associated side effects are among the most common reasons for terminating bisphosphonate therapy (24). 


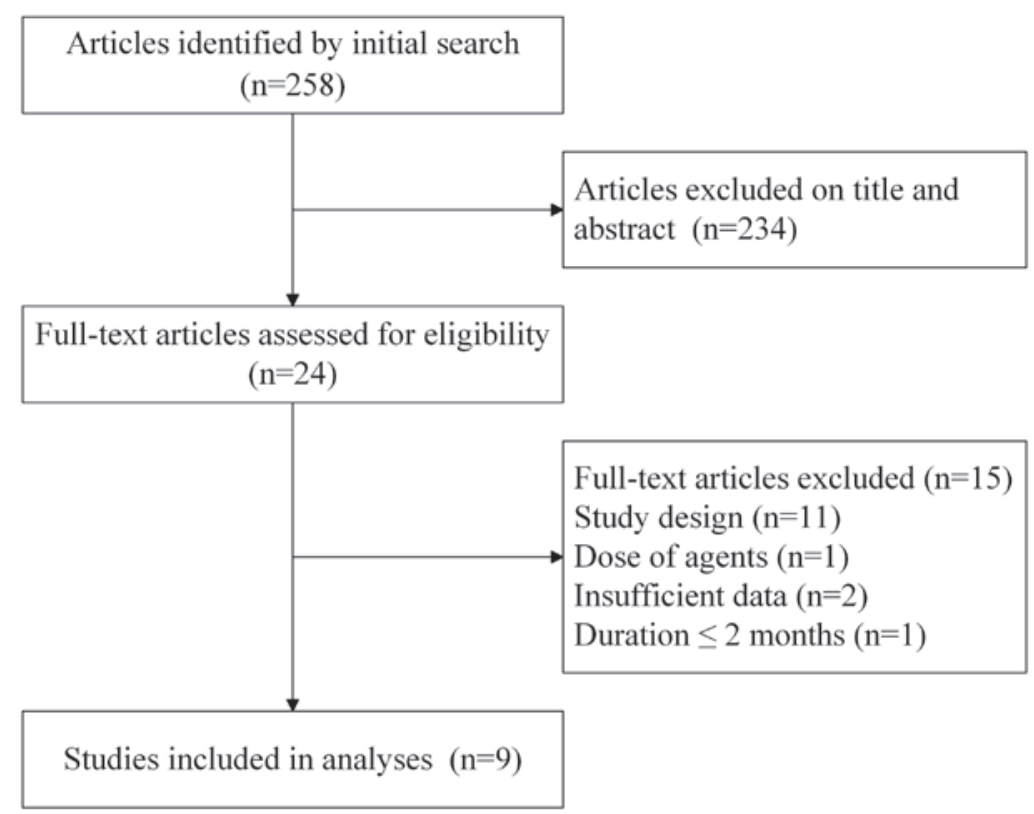

Figure 1. Flow diagram demonstrating the study selection process used in the present meta-analysis.

The present study conducted a meta-analysis of randomized, placebo-controlled trials abstracted from databases, in order to investigate the effects of Aln treatment on the risk of GIAEs in postmenopausal women with OP.

\section{Materials and methods}

Search strategy. The present study adhered to the Preferred Reporting Items for Systematic Reviews and Meta-Analysis statement guidelines for the meta-analysis of randomized controlled trials (25). A literature search for the purpose of identifying RCTs was performed. In order to identify eligible studies, the following databases were searched, with a date limit of December $30^{\text {th }}, 2014$ : Medical Literature Analysis and Retrieval System Online, Medline (http://www.ncbi.nlm.nih. gov/pubmed), Embase (http://www.embase.com), the Web of Science (http://www.thomsonscientific.com.cn/productsservices/webofscience/) and the Cochrane Central Register of Controlled Trials (http://www.cochrane.org). The search terms used were as follows: 'Osteoporosis', 'alendronate' and 'gastrointestinal'. The search was limited to English-language publications and human trials.

Study selection. Studies were included in the present meta-analysis if they met the following criteria: i) They were randomized, double-blind, placebo-controlled trials analyzed by intention-to-treat (ITT); ii) the mean age of the trial participants was at a $>50$ years old baseline; iii) the study compared the safety or tolerability profile of Aln versus a placebo for the treatment of low bone mineral density or postmenopausal women with OP; and iv) the trial was $>2$ months. The exclusion criteria were as follows: i) The study included men or lasted for $<2$ months; ii) the study did not investigate upper GIAEs as an outcome; iii) duplicate publications; and iv) only the abstract was available.

Data abstraction. Data was tabulated by two independent investigators. A double-check procedure was performed in order to ensure the accuracy of the extracted data. The following information was extracted from each study: First author, publishing year, study design, patient number, treatment strategies, and outcomes. Methodological quality of the studies was assessed using Jadad scoring (26), in which studies were scored from $0-5$, where a score of 0 corresponded to the lowest quality and a score of 5 represented the highest quality.

Statistical analysis. Analyses were conducted using the RevMan 5.3 software (The Nordic Cochrane Centre, The Cochrane Collaboration, Copenhagen, Denmark). The safety profile of Aln was evaluated on the basis of the total number of reported adverse events (AEs), AEs resulting in discontinued Aln treatment, upper GIAEs, and GIAEs resulting in discontinued Aln treatment.

The Mantel-Haenszel method was used to calculate risk ratios (RRs), and their 95\% confidence intervals (CI) were determined using either the fixed or random effects model, depending on the amount of observed heterogeneity. For heterogeneous outcomes $\left(\mathrm{I}^{2}>50 \%\right)$, a random-effects model meta-analysis was conducted, whereas, for homogeneous outcomes, a fixed-effects model meta-analysis was conducted. The effects of heterogeneity were quantified as follows: $\mathrm{I}^{2}=100 \% \times(\mathrm{Q}-\mathrm{df}) / \mathrm{Q}$, where $\mathrm{I}^{2}$ corresponded to the degree of inconsistency between the studies, and determined whether the total percentage of variation across the studies was due to heterogeneity or chance. $\mathrm{I}^{2}$ ranged between 0 and $100 \%$, where $\mathrm{I}^{2}$ values of 25,50 and $75 \%$ indicated low, moderate, and high estimates, respectively (27).

In order to detect publication bias, a sensitivity analysis was conducted using the trim and fill method or subgroup analysis. $\mathrm{P}<0.05$ was considered to indicate a statistically significant difference.

\section{Results}

Identification and selection of studies. A total of 258 studies were retrieved in the initial search of electronic databases, of 


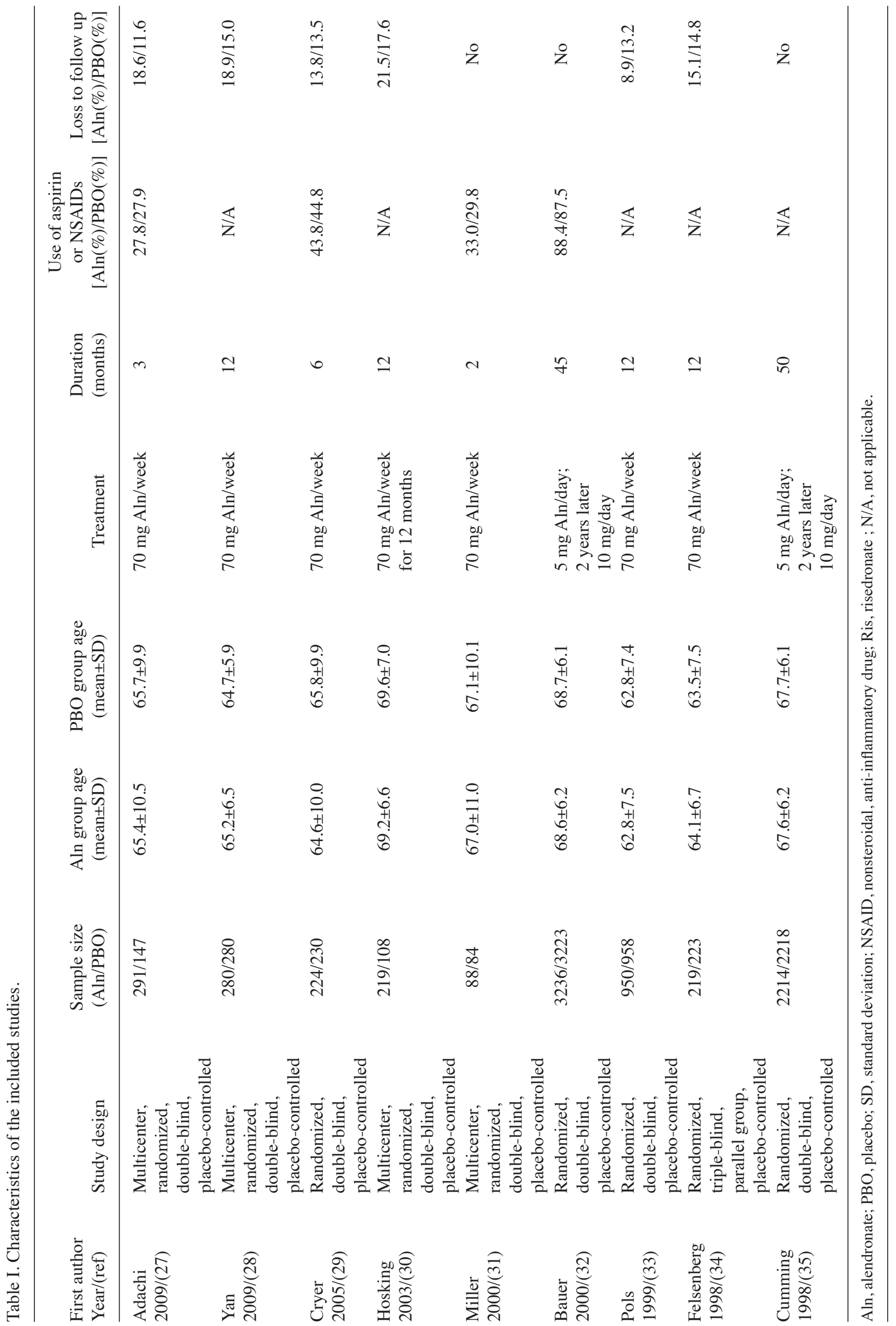




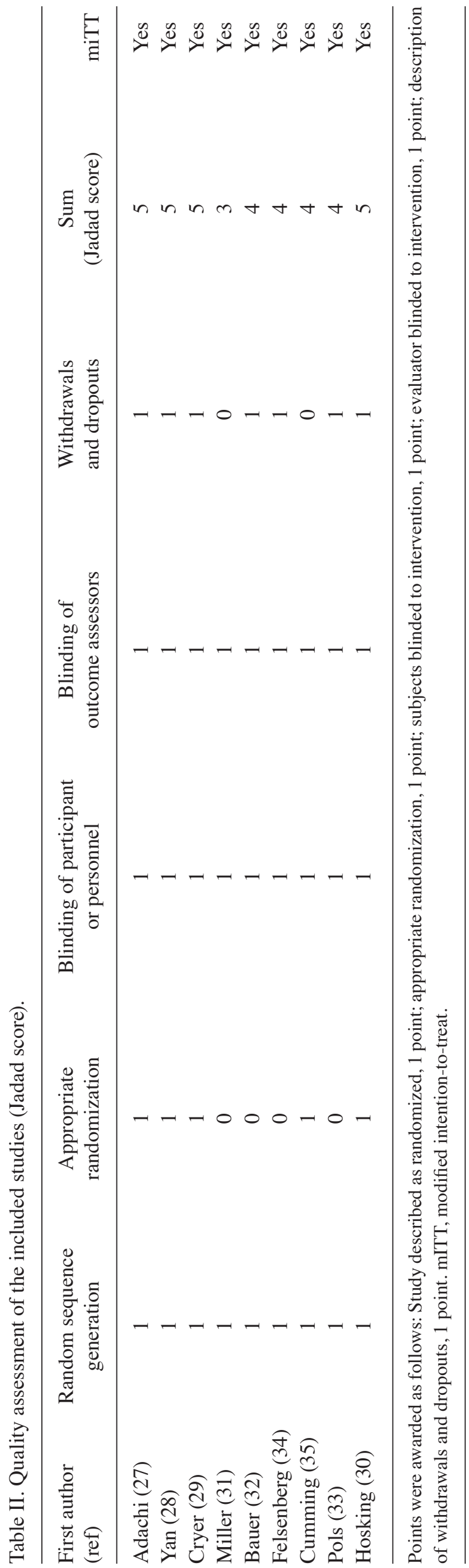

which 234 were excluded on the basis of their title and/or abstract. Of the remaining 24 studies, a total of nine RCTs were selected for inclusion in the present meta-analysis following full text reviews (28-36). A flow chart of the study selection process is presented in Fig. 1.

Study characteristics. The characteristics of the included studies are presented in Table I. A total of 15,192 participants (7,721 in the Aln group and 7,471 in the placebo group) were included in the present meta-analysis; all of which were postmenopausal women (mean age range, 62.8-69.6 years), which had previously been diagnosed with a low bone density. All the studies were randomized, double-blind, placebo-controlled trials. Two of the studies $(33,36)$ initially administered $5 \mathrm{mg}$ Aln daily; however this was later increased to $10 \mathrm{mg}$ daily, as the AEs associated with a $5 \mathrm{mg}$ Aln sodium dose have been shown to be markedly similar to those associated with the $10 \mathrm{mg}$ Aln sodium dose (37-39). As the commercial dose of Aln is $10 \mathrm{mg}$, the analyses only used the data from patients who had been treated with a $10 \mathrm{mg}$ Aln dose.

Four studies $(28,30,32,33)$ administered aspirin or a nonsteroidal anti-inflammatory drug (NSAID), to the two groups. In addition, four studies conducted a 1 year follow-up $(29,31,34,35)$, whereas two studies had a follow-up at $>1$ year $(33,36)$, and the remaining three studies had a follow-up at $<1$ year. In addition, four of the included studies (32-35) lacked appropriately described randomization, and three studies $(32,33,36)$ lacked a description of drop-outs. All the studies claimed to apply ITT analysis. The level of evidence for each article was scored from 3 to 5 , according to the Jadad quality score (Table II).

Total AEs. The risk ratio (95\% CI) of AEs occurring in postmenopausal women treated with Aln, as compared with the placebo, was 1.01 (0.97-1.06), and this was not statistically significant $(\mathrm{P}>0.05$; Fig. $2 \mathrm{~A}$ ). This outcome was attributed to heterogeneity among the included studies. A sensitivity analysis was conducted by dividing the studies into subgroups based on their duration; however, the heterogeneity remained and the results were not statistically significant. The risk ratio (95\% CI) of discontinued Aln-treatment due to the occurrence of AEs, as compared with the placebo, was 1.04 (0.91-1.19), and this was not statistically significant $(\mathrm{P}>0.05$; Fig. $2 \mathrm{~B})$. This outcome could not be attributed to heterogeneity among the studies. The sensitivity analysis demonstrated that this outcome could not be altered by omitting any single trial.

Upper GI AEs. The risk ratio (95\% CI) of upper GIAEs occurring in postmenopausal women treated with Aln, as compared with the placebo, was 1.02 (0.99-1.06), and this was not statistically significant $(\mathrm{P}>0.05$; Fig. $2 \mathrm{C})$. The heterogeneity among all studies was insignificant. The sensitivity analysis demonstrated that the overall effect could not be altered by omitting any single trial. The risk ratio (95\% CI) of the Aln-treatment of postmenopausal women being discontinued due to the occurrence of upper GIAEs, as compared with the placebo, was $1.23(0.97-1.56)$, and this was not statistically significant ( $P>0.05$; Fig. 2D). The heterogeneity among all studies was insignificant. The sensitivity analysis demonstrated that this outcome could not be altered by omitting any single trial. 
A Total AEs

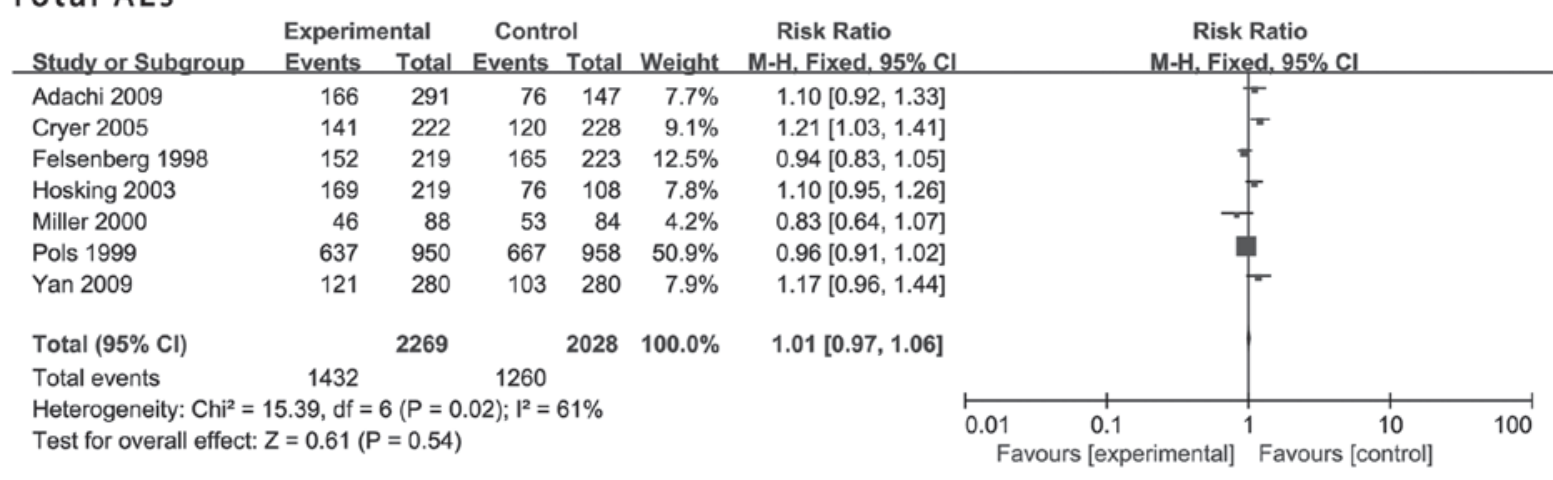

B Discontinued because of AEs

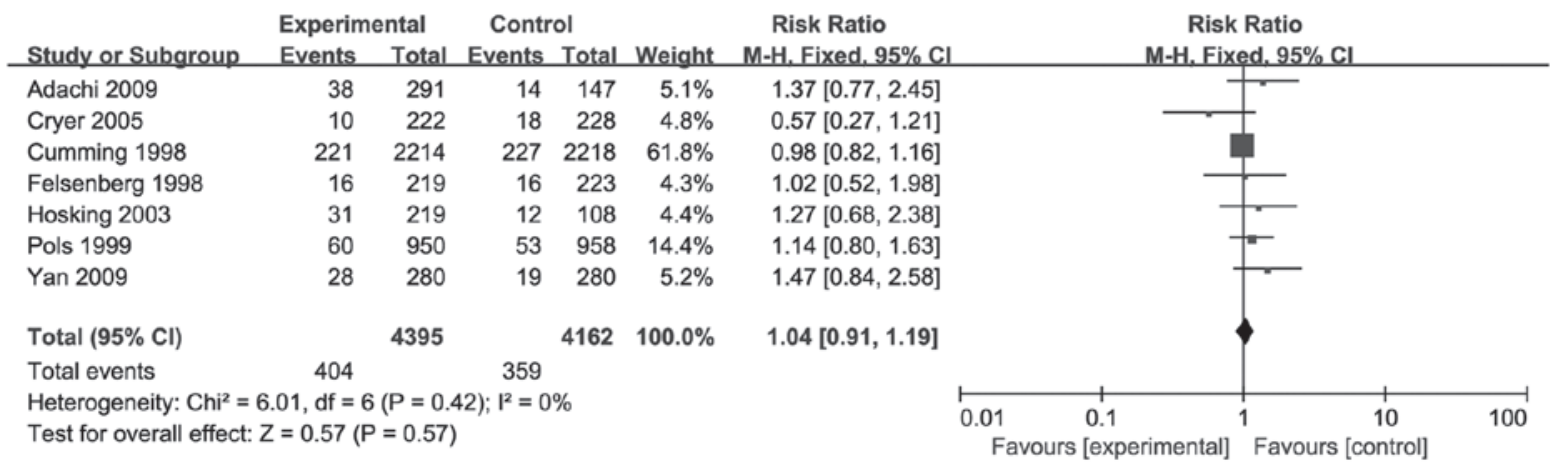

C Upper GIAEs

\begin{tabular}{|c|c|c|c|c|c|c|c|c|}
\hline \multirow[b]{2}{*}{ Study or Subgroup } & \multicolumn{2}{|c|}{ Experimental } & \multicolumn{2}{|c|}{ Control } & & \multirow{2}{*}{$\begin{array}{l}\text { Risk Ratio } \\
\text { M-H. Fixed. } 95 \% \mathrm{Cl}\end{array}$} & \multirow{2}{*}{\multicolumn{2}{|c|}{$\begin{array}{c}\text { Risk Ratio } \\
\text { M-H. Fixed. } 95 \% \mathrm{Cl}\end{array}$}} \\
\hline & Events & Total & Events & Total & Weight & & & \\
\hline Adachi 2009 & 66 & 291 & 30 & 147 & $1.3 \%$ & $1.11[0.76,1.63]$ & & \\
\hline Bauer 2000 & 1536 & 3236 & 1490 & 3223 & $50.2 \%$ & $1.03[0.97,1.08]$ & & \\
\hline Cryer 2005 & 51 & 222 & 53 & 228 & $1.8 \%$ & $0.99[0.71,1.38]$ & & \\
\hline Cumming 1998 & 1052 & 2214 & 1047 & 2218 & $35.2 \%$ & $1.01[0.95,1.07]$ & & \\
\hline Felsenberg 1998 & 49 & 219 & 54 & 223 & $1.8 \%$ & $0.92[0.66,1.30]$ & & \\
\hline Hosking 2003 & 62 & 219 & 29 & 108 & $1.3 \%$ & $1.05[0.72,1.54]$ & - & \\
\hline Miller 2000 & 24 & 88 & 23 & 84 & $0.8 \%$ & $1.00[0.61,1.62]$ & & \\
\hline Pols 1999 & 202 & 950 & 185 & 958 & $6.2 \%$ & $1.10[0.92,1.32]$ & 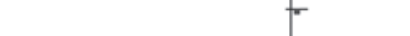 & \\
\hline Yan 2009 & 47 & 280 & 43 & 280 & $1.4 \%$ & $1.09[0.75,1.60]$ & & \\
\hline Total $(95 \% \mathrm{Cl})$ & & 7719 & & 7469 & $100.0 \%$ & $1.02[0.99,1.06]$ & & \\
\hline Total events & 3089 & & 2954 & & & & & \\
\hline $\begin{array}{l}\text { Heterogeneity: } \mathrm{Chi}^{2}= \\
\text { Test for overall effect: }\end{array}$ & $\begin{array}{l}.66, d f=8 \\
z=1.22(R\end{array}$ & $\begin{array}{l}(P=0.9 \\
=0.22)\end{array}$ & $99) ; 1^{2}=0$ & & & & 0.1 & 100 \\
\hline
\end{tabular}

D Discontinued because of upper GIAEs

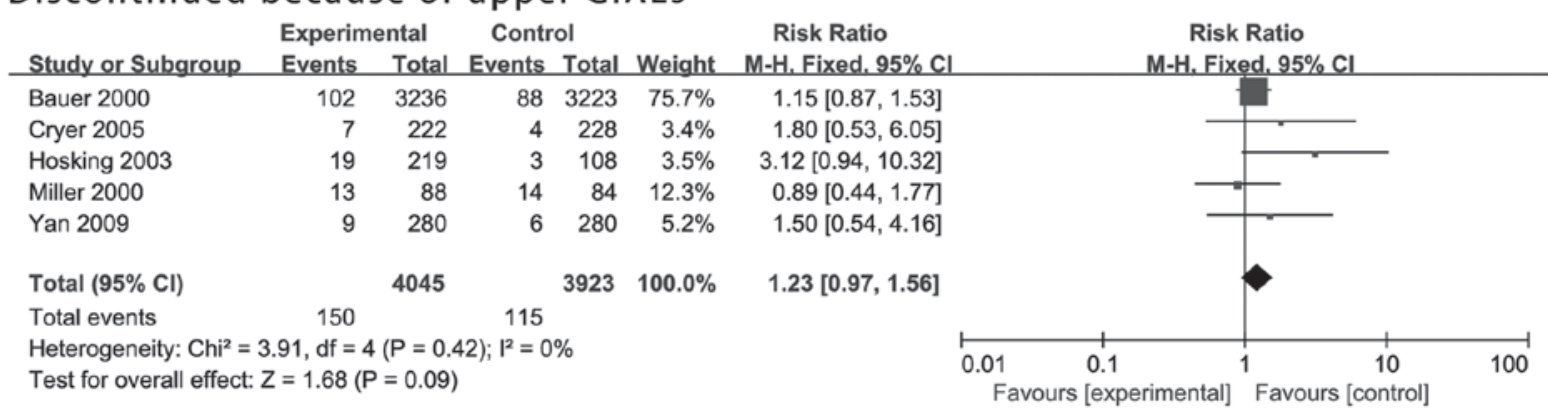

Figure 2. The relative risk of (A) AEs, (B) discontinued Aln treatment due to AEs, (C) upper GIAEs and (D) discontinued Aln treatment due to GIAEs in the Aln-treated groups, as compared with the placebo-treated groups of all included studies. AEs, adverse events; GIAEs, gastrointestinal adverse events; Aln, alendronate; M-H, Mantel-Haenszel method; CI, confidence interval.

Individual upper GIAEs. Individual upper GIAEs, including abdominal pain, nausea, dyspepsia, acid regurgitation, vomiting, gastroesophageal reflux and esophagitis, were the most common upper GIAEs reported among the studies. No significant differences in the incidence of individual GIAEs between the Aln-treated and placebo-treated groups were observed (Table III). The heterogeneity across the studies was insignificant. The sensitivity analysis demonstrated that this outcome could not be altered by omitting any single trial. 
Table III. Patients with upper GIAEs.

\begin{tabular}{|c|c|c|c|c|c|}
\hline \multirow[b]{2}{*}{ Upper GIAE } & \multirow[b]{2}{*}{ No. of studies } & \multicolumn{2}{|c|}{ No. $(\%)$ of patients } & \multirow[b]{2}{*}{$\mathrm{RR}(95 \% \mathrm{CI})$} & \multirow[b]{2}{*}{ P-value } \\
\hline & & Aln & $\mathrm{PBO}$ & & \\
\hline Abdominal pain & 7 & 910 (12.6) & 877 (12.2) & $1.04(0.95-1.13)$ & 0.41 \\
\hline Nausea & 6 & $445(8.9)$ & $458(9.2)$ & $0.97(0.86-1.10)$ & 0.62 \\
\hline Dyspepsia & 5 & $639(13.4)$ & $674(14.1)$ & $0.94(0.86-1.04)$ & 0.25 \\
\hline Acid regurgitation & 5 & $467(6.9)$ & $445(6.6)$ & $1.05(0.92-1.19)$ & 0.47 \\
\hline Vomiting & 5 & $136(2.8)$ & $130(2.7)$ & $1.04(0.82-1.32)$ & 0.72 \\
\hline $\begin{array}{l}\text { Gastroesophageal } \\
\text { reflux }\end{array}$ & 4 & $81(1.8)$ & $88(2.0)$ & $0.91(0.68-1.23)$ & 0.55 \\
\hline Esophagitis & 4 & $49(0.8)$ & $32(0.5)$ & $1.53(0.98-2.38)$ & 0.06 \\
\hline
\end{tabular}

GIAE, gastrointestinal adverse events; Aln, alendronate; PBO, placebo; RR, risk ratio; CI, confidence interval.

\section{Discussion}

The present study conducted a meta-analysis of results from RCTs in the literature, in order to investigate the effects of Aln treatment on the risk of upper GIAEs in postmenopausal women with OP. A total of 258 studies were identified in the initial database search, of which nine RCTs met the inclusion criteria of the present study.

Previous studies have not identified a causative link between upper GIAEs and Aln treatment; however, the GI safety profile of bisphosphonates has been a concern in clinical practice (20-23). The present study enrolled a broader patient population and had a longer duration, as compared with previous trials. In addition, all the included studies were of a good quality. To the best of our knowledge, the present study is the first to evaluate upper GIAEs as a primary outcome; thus suggesting that our results would be more robust.

The duration of the studies included in the present meta-analysis ranged from 2 months to 4.2 years. Landfeldt et al (40) previously demonstrated that the incidence of upper GIAEs was inversely associated with the duration of treatment with Aln. However, some patients have demonstrated superior GI tolerability, whereas others have discontinued therapy after a shorter period of time. Therefore, it would be unreliable to only measure the incidence of upper GIAEs in patients who have persisted with therapy for a specific duration. In addition, if the analysis was restricted to patients who had remained on treatment for a specific duration, it would not be possible to generalize the results to the population of interest.

The treatment of patients with aspirin or NSAIDs was not included in the exclusion criteria $(28,30,32,33)$, yet the presence of active GI tract disease, the need for anti-secretory therapy, and the use of aspirin or NSAIDs may have increased the risk of experiencing an upper GIAE in both the Aln-treated and placebo-treated groups (41). However, the effects of these risk factors were similar among the treatment groups.

The incidence of AEs was greater in the patients in the Aln-treated group, as compared with the placebo-treated group; however, the difference in the safety profile of Aln was not statistically significant between these groups. It should be noted that heterogeneity existed among the studies. A sensitivity analysis was conducted by dividing the studies into subgroups based on the study duration. In particular, the studies were divided into three subgroups: i) Duration $<1$ year; ii) duration $=1$ year; and iii) duration $>1$ year. However, heterogeneity was still detected. Notably, the overall outcome could not be altered by omitting a single study.

The results of the present meta-analysis are consistent with those from previous studies (28-36), which also observed no significant difference in the frequency of upper GIAEs between placebo-treated and Aln-treated groups, and demonstrated that the GI safety and tolerability profile of Aln resembles the placebo $(10,11)$. However, the present results contradict a previous study that suggested that Aln treatment may be associated with an increased risk of upper GIAEs in patients, as compared with no treatment (17). Furthermore, in the present study, the incidences of the primary individual upper GIAEs, including abdominal pain, nausea, dyspepsia, acid regurgitation, vomiting, gastroesophageal reflux and esophagitis, were not significantly different between the placebo- and Aln-treated groups. This is inconsistent with a previous study that suggested that patients treated with Aln developed specific GIAEs, including dyspepsia and upper abdominal pain (42).

Notably, oral bisphosphonates have fairly complex administration instructions (taken alone with $240 \mathrm{ml}$ of water after fasting overnight, and remaining upright for at least $30 \mathrm{~min}$ ), and poor compliance to these has previously been associated with an increased risk of GIAEs (11). This may explain why some studies have reported an increased risk of upper GIAEs in patients treated with Aln, and suggests that patients should strictly adhere to the treatment instructions when taking Aln.

The present study has some limitations: Firstly, the demographic was restricted to postmenopausal OP, and thus the results may not be extrapolated to patients with other conditions; secondly, although the database searches were extensive, we cannot be entirely sure that all relevant articles were included; and thirdly, the analysis was only based on published data.

In conclusion, the results from the present meta-analysis suggested that daily treatment with $10 \mathrm{mg}$ Aln sodium was 
not associated with an increased incidence of GIAEs, thus suggesting that Aln may be considered safe for the treatment of postmenopausal women with OP.

\section{Acknowledgements}

Dr Manru Zhou, Dr Yayuan Zheng and Professor Yuyu Liu were involved in the study selection, quality assessment of the selected studies, data extraction and analysis, and the writing of the manuscript. Professor Yuyu Liu takes responsibility for the integrity of the data analysis and critical revision of article. The present study was funded by grants from the National Natural Science Foundation of China (grant no. 81102450) and the Guangdong Province Science and Technology Plan (grant no. 2012B031800225) and the Characteristic Innovation Project (Natural Science) of the Education Department of Guangdong Province (grant no. 2014KTSCX084).

\section{References}

1. Orimo H, Nakamura T, Hosoi T, Iki M, Uenishi K, Endo N, Ohta H, Shiraki M, Sugimoto T, Suzuki T, et al: Japanese 2011 guidelines for prevention and treatment of osteoporosis - executive summary. Arch Osteoporos 7: 3-20, 2012.

2. Brown JP and Josse RG; Scientific Advisory Council of the Osteoporosis Society of Canada: 2002 clinical practice guidelines for the diagnosis and management of osteoporosis in Canada. CMAJ 167 (10 Suppl): S1-S34, 2002.

3. Kanis JA, Burlet N, Cooper C, Delmas PD, Reginster JY, Borgstrom F and Rizzoli R; European Society for Clinical and Economic Aspects of Osteoporosis and Osteoarthritis (ESCEO): European guidance for the diagnosis and management of osteoporosis in postmenopausal women. Osteoporos Int 19: 399-428, 2008.

4. Hodgson SF, Watts NB, Bilezikian JP, Clarke BL, Gray TK, Harris DW, Johnston CC Jr, Kleerekoper M, Lindsay R, Luckey MM, et al; AACE Osteoporosis Task Force: American Association of Clinical Endocrinologists medical guidelines for clinical practice for the prevention and treatment of postmenopausal osteoporosis: 2001 edition, with selected updates for 2003. Endocr Pract 9: 544-564, 2003.

5. Body JJ, Bergmann P, Boonen S, Boutsen Y, Devogelaer JP, Goemaere S, Kaufman JM, Rozenberg S and Reginster JY: Evidence-based guidelines for the pharmacological treatment of postmenopausal osteoporosis: A consensus document by the Belgian Bone Club. Osteoporos Int 21: 1657-1680, 2010.

6. Qaseem A, Snow V, Shekelle P, Hopkins R Jr, Forciea MA and Owens DK; Clinical Efficacy Assessment Subcommittee of the American College of Physicians: Pharmacologic treatment of low bone density or osteoporosis to prevent fractures: A clinical practice guideline from the American College of Physicians. Ann Intern Med 149: 404-415, 2008.

7. Murad MH, Drake MT, Mullan RJ, Mauck KF, Stuart LM, Lane MA, Abu Elnour NO, Erwin PJ, Hazem A, Puhan MA, et al: Clinical review. Comparative effectiveness of drug treatments to prevent fragility fractures: A systematic review and network meta-analysis. J Clin Endocrinol Metab 97: 1871-1880, 2012.

8. Wells GA, Cranney A, Peterson J, Boucher M, Shea B, Robinson V, Coyle D and Tugwell P: Alendronate for the primary and secondary prevention of osteoporotic fractures in postmenopausal women. Cochrane Database Syst Rev 23: CD001155, 2008.

9. Mackey DC, Black DM, Bauer DC, McCloskey EV, Eastell R, Mesenbrink P, Thompson JR and Cummings SR: Effects of antiresorptive treatment on nonvertebral fracture outcomes. J Bone Miner Res 26: 2411-2418, 2011.

10. Bobba RS, Beattie K, Parkinson B, Kumbhare D and Adachi JD: Tolerability of different dosing regimens of bisphosphonates for the treatment of osteoporosis and malignant bone disease. Drug Saf 29: 1133-1152, 2006.

11. Strampel W, Emkey R and Civitelli R: Safety considerations with bisphosphonates for the treatment of osteoporosis. Drug Saf 30: 755-763, 2007.
12. Cadarette SM, Katz JN, Brookhart MA, Stürmer T, Stedman MR, Levin R and Solomon DH: Comparative gastrointestinal safety of weekly oral bisphosphonates. Osteoporos Int 20: 1735-1747, 2009.

13. Miller R, Bolognese M, Worley K, Sollis A and Sheer R: Incidence of gastrointestinal events among bisphosphonate patients in an observational setting. Am J Manag Care 10: S207-S215, 2004.

14. Kane S, Borisov N and Brixner D: Pharmacoeconomic evaluation of gastrointestinal tract events during treatment with risedronate or alendronate : A retrospective cohort study. Am J Manag Care 10: S216-S226, 2004.

15. Ste-Marie LG, Brown JP, Beary JF, Matzkin E, Darbie LM, Burgio DE and Racewicz AJ: Comparison of the effects of once-monthly versus once-daily risedronate in postmenopausal osteoporosis: A phase II, 6-month, multicenter, randomized, double-blind, active-controlled, dose-ranging study. Clin Ther 31: 272-285, 2009.

16. MacLean C, Newberry S, Maglione M, McMahon M, Ranganath V, Suttorp M, Mojica W, Timmer M, Alexander A, McNamara M, et al: Systematic review: Comparative effectiveness of treatments to prevent fractures in men and women with low bone density or osteoporosis. Ann Intern Med 148: 197-213, 2008.

17. Landfeldt E, Lang A, Robbins S and Ström O: Gastrointestinal tolerability and patterns of switching in patients treated for primary osteoporosis: The Swedish Adherence Register Analysis (SARA). Calcif Tissue Int 89: 234-245, 2011.

18. Reid IR: Osteoporosis treatment: Focus on safety. Eur J Intern Med 24: 691-697, 2013.

19. Fleisch H: Bisphosphonates in osteoporosis. Eur Spine J 12 (Suppl 2): S142-146, 2003.

20. Oh YH, Yoon C and Park SM: Bisphosphonate use and gastrointestinal tract cancer risk: Meta-analysis of observational studies. World J Gastroenterol 18: 5779-5788, 2012.

21. Rossini M, Bianchi G, Di Munno O, Giannini S, Minisola S, Sinigaglia L and Adami S; Treatment of Osteoporosis in clinical Practice (TOP) Study Group: Determinants of adherence to osteoporosis treatment in clinical practice. Osteoporos Int 17: 914-921, 2006

22. Shiraki M, Yamazaki Y, Kuroda T, Tanaka S and Miyata K: Serum level of pepsinogen significantly associated with gastric distress induced by amino-bisphosphonates. Osteoporos Int 22: 1717-1723, 2011.

23. Papaioannou A, Kennedy CC, Dolovich L, Lau E and Adachi JD: Patient adherence to osteoporosis medications. Problems, consequences and management strategies. Drugs Aging 24: 37-55, 2007.

24. Tosteson AN, Grove MR, Hammond CS, Moncur MM, Ray GT, Hebert GM, Pressman AR and Ettinger B: Early discontinuation of treatment for osteoporosis. Am J Med 115: 209-216, 2003

25. Liberati A, Altman DG, Tetzlaff J, Mulrow C, Gøtzsche PC Ioannidis JP, Clarke M, Devereaux PJ, Kleijnen J and Moher D: The PRISMA statement for reporting systematic reviews and meta-analyses of studies that evaluate health care interventions: Explanation and elaboration. PLoS Med 6: e1000100, 2009.

26. Jadad AR, Moore RA, Carroll D, Jenkinson C, Reynolds DJ, Gavaghan DJ and McQuay HJ: Assessing the quality of reports of randomized clinical trials: Is blinding necessary? Control Clin Trials 17: 1-12, 1996

27. Higgins JPT and Green S (eds): Cochrane Handbook for Systematic Reviews of Interventions Version 5.0.1. In: The Cochrane Collaboration, 2008.

28. Adachi JD, Faraawi RY, O'Mahony MF, Nayar A, Massaad R, Evans JK and Yacik C: Upper gastrointestinal tolerability of alendronate sodium monohydrate $10 \mathrm{mg}$ once daily in postmenopausal women: A 12-week, randomized, double-blind, placebo-controlled, exploratory study. Clin Ther 31: 1747-1753, 2009.

29. Yan Y, Wang W, Zhu H, Li M, Liu J, Luo B, Xie H, Zhang G and Li F: The efficacy and tolerability of once-weekly alendronate $70 \mathrm{mg}$ on bone mineral density and bone turnover markers in postmenopausal Chinese women with osteoporosis. J Bone Miner Metab 27: 471-478, 2009.

30. Cryer B, Binkley N, Simonelli C, Lewiecki EM, Lanza F, Chen E, Petruschke RA, Mullen C and de Papp AE: A randomized, placebo-controlled, 6-month study of once-weekly alendronate oral solution for postmenopausal osteoporosis. Am J Geriatr Pharmacother 3: 127-136, 2005. 
31. Hosking D, Adami S, Felsenberg D, Andia JC, Välimäki M, Benhamou L, Reginster JY, Yacik C, Rybak-Feglin A, Petruschke RA, et al: Comparison of change in bone resorption and bone mineral density with once-weekly alendronate and daily risedronate: A randomised, placebo-controlled study. Curr Med Res Opin 19: 383-394, 2003.

32. Miller PD, Woodson G, Licata AA, Ettinger MP, Mako B, Smith ME, Wang L, Yates SJ, Melton ME and Palmisano JJ Rechallenge of patients who had discontinued alendronate therapy because of upper gastrointestinal symptoms. Clin Ther 22: 1433-1442, 2000.

33. Bauer DC, Black D, Ensrud K, Thompson D, Hochberg M, Nevitt M, Musliner T and Freedholm D: Upper gastrointestinal tract safety profile of alendronate: The fracture intervention trial. Arch Intern Med 160: 517-525, 2000.

34. Pols HA, Felsenberg D, Hanley DA, Stepán J, Muñoz-Torres M, Wilkin TJ, Qin-sheng G, Galich AM, Vandormael K, Yates AJ and Stych B: Multinational, placebo-controlled, randomized trial of the effects of alendronate on bone density and fracture risk in postmenopausal women with low bone mass: Results of the FOSIT study. Fosamax International Trial Study Group. Osteoporos Int 9: 461-468, 1999.

35. Felsenberg D, Alenfeld F, Bock O, Hammermeister C and Gowan W: Placebo-controlled multicenter study of oral alendronate in postmenopausal osteoporotic women. Maturitas 31: 35-44, 1998.

36. Cummings SR, Black DM, Thompson DE, Applegate WB, Barrett-Connor E, Musliner TA, Palermo L, Prineas R, Rubin SM, Scott JC, et al: Effect of alendronate on risk of fracture in women with low bone density but without vertebral fractures: Results from the Fracture Intervention Trial. JAMA 280: 2077-2082, 1998.
37. Liberman UA, Weiss SR, Bröll J, Minne HW, Quan H, Bell NH, Rodriguez-Portales J, Downs RW Jr, Dequeker J and Favus M: Effect of oral alendronate on bone mineral density and the incidence of fractures in postmenopausal osteoporosis. The Alendronate Phase III Osteoporosis Treatment Study Group. N Engl J Med 333: 1437-1443, 1995.

38. Tucci JR, Tonino RP, Emkey RD, Peverly CA, Kher U and Santora AC II: Effect of three years of oral alendronate treatment in postmenopausal women with osteoporosis. Am J Med 101: 488-501, 1996.

39. Devogelaer JP, Broll H, Correa-Rotter R, Cumming DC, De Deuxchaisnes CN, Geusens P, Hosking D, Jaeger P, Kaufman JM, Leite M, et al: Oral alendronate induces progressive increases in bone mass of the spine, hip, and total body over 3 years in postmenopausal women with osteoporosis. Bone 18: 141-150, 1996.

40. Landfeldt E, Ström O, Robbins S and Borgström F: Adherence to treatment of primary osteoporosis and its association to fractures - the Swedish Adherence Register Analysis (SARA). Osteoporos Int 23: 433-443, 2012.

41. Taggart H, Bolognese MA, Lindsay R, Ettinger MP, Mulder $H$, Josse RG, Roberts A, Zippel H, Adami S, Ernst TF and Stevens KP: Upper gastrointestinal tract safety of risedronate: A pooled analysis of 9 clinical trials. Mayo Clin Proc 77: 262-270, 2002.

42. Hadji P, Gamerdinger D, Spieler W, Kann PH, Loeffler H, Articus K, Möricke R and Ziller V: Rapid Onset and Sustained Efficacy (ROSE) study: Results of a randomised, multicentre trial comparing the effect of zoledronic acid or alendronate on bone metabolism in postmenopausal women with low bone mass. Osteoporos Int 23: 625-633, 2012. 